\title{
INFORME EN DERECHO SOBRE PRECEDENTES JURISDICCIONALES EN MATERIA DE MEDIA PRESCRIPCIÓN*
}

\author{
Humberto Nogueira Alcalá**
}

\section{Las fuentes del derecho que delimitan y configuran el bloque constitucional de derechos fundamentales.}

La Constitución Política de la República, en su artículo $1^{\circ}$, inciso $1^{\circ}$, determina que "las personas nacen libres e iguales en dignidad y derechos".

La dignidad es una cualidad intrínseca, irrenunciable e inalienable del ser humano, constituyendo un elemento que cualifica al ser humano en cuanto tal, siendo una cualidad integrante e irrenunciable de la condición humana. Ella es asegurada, respetada, garantizada y promovida por el orden jurídico estatal e internacional.

A su vez, el Pacto Internacional de Derechos Civiles y Políticos de 19 de diciembre de 1966, en su preámbulo afirma que "el reconocimiento de la dignidad inherente a todos los miembros de la sociedad humana [...] constituye el fundamento de la libertad, la justicia y la paz mundial, en el reconocimiento que esos derechos derivan de la dignidad inherente a los hombres".

La dignidad es así un valor inherente a la persona humana que se manifiesta a través de la autodeterminación consciente y responsable de su vida y que exige el respeto de ella por los demás. La dignidad de la persona se constituye en el valor supremo y en el principio jurídico que constituye la columna vertebral básica de todo el ordenamiento constitucional y es fuente de todos los derechos fundamentales, irradiando todo el sistema jurídico el que debe interpretarse y aplicarse conforme a las condiciones en que dicha dignidad se realice de mejor forma.

* Trabajo recibido el 5 de agosto de 2008; aprobada su publicación el 3 de septiembre de 2008. Informe solicitado por la unidad de Derechos Humanos del Ministerio del Interior.

* Doctor en Derecho Constitucional, Universidad Católica de Lovaina La Nueva, Profesor titular de Derecho Constitucional y Director del Centro de Estudios Constitucionales de Chile, Universidad de Talca, Campus Santiago. Correo electrónico: nogueira@utalca.cl. 
Peter Häberle señala que la dignidad de la persona humana consiste en el "valor y pretensión de respeto intrínseco y simultáneamente social, al cual pertenece cada ser humano por su condición humana"1.

El artículo $1^{\circ}$, inciso $1^{\circ}$ de la Constitución, constituye una norma directriz a través de la cual debe iluminarse e interpretarse todo el resto del texto constitucional y del ordenamiento jurídico nacional, constituye una pauta interpretativa que debe ser seguida por todos los operadores jurídicos, en cuanto norma rectora suprema de nuestro ordenamiento jurídico. Asimismo, como señala Ríos Álvarez, la dignidad de la persona tiene también el carácter de contenido integrador del vacío que puede llegar a producir la falta de reconocimiento o la omisión de un derecho indispensable o esencial a la preservación de la persona humana ${ }^{2}$.

Nuestro Tribunal Constitucional, en su sentencia sobre la "Unidad de análisis financiero y modificación del Código Penal en materia de lavados y blanqueo de activos", ha establecido sobre la materia:

"Que en tal orden de ideas cabe recordar, primeramente, por ser base del sistema constitucional imperante en Chile, el artículo $1^{\circ}$ inciso primero de la Constitución, el cual dispone que "las personas nacen libres e iguales en derechos". Pues bien, la dignidad a la cual se alude es aquel principio capital de nuestro Código Supremo es la cualidad de ser humano que lo hace acreedor siempre a un trato de respeto, porque ella es la fuente de los derechos esenciales y de las garantías destinadas a obtener que sean resguardados"3.

El respeto y protección de la dignidad del ser humano delimitan la potestad constituyente y la potestad estatal.

Una Constitución que se compromete con la dignidad de la persona humana establece una premisa antropológica-cultural y precisa los contornos de su comprensión del Estado Constitucional.

Los ámbitos de la dignidad humana que deben asumirse aplicando la pauta normativa de nuestro artículo $1^{\circ}$, inciso $1^{\circ}$, de la Carta Fundamental, son las dimensiones ontológicas dadas

1 Háberle, Peter. "A dignidade humana como fundamento da comunidade estatal”, en Wolfgang Sarlet, Ingo (Org.). Dimensoes da Dignidade. Ed. Livraria Do Advogado. Porto Alegre. 2005. p. 104.

2 Ríos Álvarez, Lautaro. 1985. La dignidad de la persona en el ordenamiento jurídico español. En obra colectiva, XV Jornadas Chilenas de Derecho Público, Valparaíso, Universidad de Valparaíso, página 205 .

3 Sentencia del Tribunal Constitucional, Rol No 389, de fecha veintiocho de octubre de 2003, considerando decimoséptimo. 
por la racionalidad y libertad del ser humano (autodeterminación conciente y responsable de su propia vida), como asimismo la de carácter ético o deontológico constituidas por la autonomía $\mathrm{y}$ fin en si mismo, no siendo la persona un medio o instrumento de nadie.

La noción de dignidad humana es producto del reconocimiento de la unicidad de cada individuo humano y del hecho de que ella es creadora de un deber de igual respeto y protección en el ámbito de la sociedad ${ }^{4}$.

En esta materia, la Corte Interamericana de Derechos Humanos se ha pronunciado en diversos casos específicos, mencionaremos a continuación uno de los primeros pronunciamientos en la materia:

"La práctica de desapariciones, a mas de violar directamente numerosas disposiciones de la Convención, [...], significa una ruptura radical de este tratado, en cuanto implica un craso abandono de los valores que emanan de la dignidad humana y de los principios que mas profundamente fundamentan el sistema interamericano y la misma Convención".

Obviamente, el orden material de valores que implica la dignidad humana, como asimismo la libertad e igualdad esencial de todos los seres humanos es considerado por la Constitución chilena como anteriores a ella misma, en la medida que el texto de la Carta Fundamental no crea dichos valores, sino que se limita a reconocerlos, asegurarlos y garantizarlos, su fundamento último se encuentra en la idea de ser humano que asume la cultura occidental.

La dignidad de la persona es la fuente y fundamento de los derechos a través de los cuales se funda el consenso de la sociedad y se legitima el Estado, además de las garantías básicas para el desarrollo de la República Democrática y del Estado de Derecho.

\section{Los derechos fundamentales.}

El artículo $5^{\circ}$ inciso $2^{\circ}$ de la Constitución prescribe «El ejercicio de la soberanía reconoce como limitación el respeto de los derechos esenciales que emanan de la naturaleza humana".

En el sistema constitucional chileno los derechos no están en las normas (internas o internacionales),»no se constituyen» en la norma positiva sino que ella sólo los asegura, los

$4 \quad$ Wolfgang Sarlet, Ingo. "As dimensoes da dignidade da Pessoa Humana”, en Wolfgang Sarlet, Ingo (Org.). Dimensoes da Dignidade. Ed. Livraria Do Advogado. Porto Alegre. 2005. p.26.

5 Sentencia Corte Interamericana de Derechos Humanos, Caso Velásquez Rodríguez vs. Honduras. Serie C $\mathrm{N}^{\circ} 4$, fundamento 158 . 
respeta, los garantiza y los promueve, los derechos emanan de la dignidad humana. Los derechos tampoco se realizan en las normas sino que ellos se concretan en la vigencia sociológica, la que demuestra la efectividad de los derechos. La norma positiva solo significa vigencia normonológica ${ }^{6}$.

La Constitución explicita un aseguramiento genérico a la existencia de derechos esenciales lo que da lugar a un catálogo de derechos abierto, ya que el constituyente reconoce sus eventuales limitaciones y está conciente del desarrollo progresivo de los derechos y garantías acorde a la naturaleza y necesidades esenciales del ser humano.

Hay una sola fuente de la fundamentalidad de los derechos, su relación con la dignidad humana, ya que son expresión inmediata y positiva de la misma, constituyendo el núcleo básico irreductible e irrenunciable del status jurídico de la persona. Por otra parte, tal denominación denota el carácter de fundamento del orden jurídico y político de la convivencia en sociedad de tales derechos, constituyendo elementos básicos del ordenamiento jurídico.

Los derechos fundamentales en cuanto tienen su fuente en la dignidad humana y en cuanto buscan el libre desarrollo de la persona, exigen del ordenamiento jurídico positivo su protección y garantía. De hecho, puede reconocerse la existencia de derechos fundamentales implícitos o de derechos que serán reconocidos en el futuro como tales, dadas nuevas realidades del desarrollo de la existencia humana y de nuevos contextos de las sociedades políticas futuras.

Como señala Ferrajoli, «Lo que no puede consentirse es la falacia realista de la reducción del derecho al hecho y la determinista de la identificación de lo que acontece con lo que no puede dejar de acontecer» ${ }^{7}$.

El nexo entre expectativas y derechos garantizados no es de naturaleza empírica sino normativa, «la ausencia de garantías debe ser considerado como una indebida laguna que los poderes públicos internos e internacionales tienen la obligación de colmar» ${ }^{8}$, la cual puede ser superada por una interpretación integradora de los derechos y sus garantías.

El profesor Cea Egaña señala que los derechos fundamentales son aquellos "derechos, libertades, igualdades o inviolabilidades que, desde la concepción, fluyen de la dignidad humana y que son intrínsecos de la naturaleza singularísima del titular de esa dignidad. Tales atributos,

\footnotetext{
6 Bidart Campos, Germán. 1998. La interpretación de los derechos humanos en la jurisdicción internacional e interna. En V Congreso Iberoamericano de Derecho Constitucional. Ed. UNAM, México, página 98. Ferrajoli, Luigi. Derechos y garantías. Op.cit. pag.65

Ferrajoli, Luigi. Op.cit. pág. 63.
} 
facultades o derechos públicos subjetivos son, y deben ser siempre, reconocidos y protegidos por el ordenamiento jurídico, permitiendo al titular exigir su cumplimiento con los deberes correlativos" $"$

Los derechos fundamentales no son únicamente los asegurados expresamente en el texto constitucional, ya que además se encuentran los derechos implícitos, los cuales tienen expreso reconocimiento en la jurisprudencia del Tribunal Constitucional.

El Tribunal Constitucional, en sentencia Rol $N^{\circ} 226$ de 30 de Octubre de 1995, considerando $25^{\circ}$, determina:

“... la doctrina como nuestra Constitución Política reconocen la existencia de derechos, aunque no estén consagrados en el texto constitucional, a menos que esta consagración implique una violación a las normas fundamentales".

"Esta última expresión significa que los hombres son titulares de derechos por ser tales, sin que sea menester que se aseguren constitucionalmente para que gocen de la protección constitucional".

Los derechos implícitos no solo tienen reconocimiento jurisprudencial, sino que tienen reconocimiento normativo vinculante y obligatorio para los operadores jurídicos nacionales, en la medida que están expresamente consagrados en el artículo 29 de la Convención Americana de Derechos Humanos. 477/95:

Por dicha razón, tal como lo determina la Corte Constitucional de Colombia en sentencia

«De un lado, el artículo 29 inciso c), de la Convención Americana, nos permite comprender el efecto vinculante de otros derechos que, aún cuando no fueron expresamente recogidos por los pactos internacionales ratificados por Colombia, quedaron implícitamente garantizados en virtud de tal disposición.

La disposición contenida en el literal c) del artículo 29, establece de un lado la expresa prohibición de excluir los derechos inherentes al ser humano y, por otra parte, otorga un amplio sentido de interpretación de los derechos inherentes a la persona, tal significación permite considerar el derecho a la identidad consagrado de manera implícita en todos los pactos o convenios de carácter internacional, y en consecuencia objeto de protección jurídica.»

9 Cea Egaña, José Luis. Derecho Constitucional chileno. Tomo I. Editorial de la Universidad Católica de Chile, Santiago, Chile, 2002, página 221. 
El artículo 29, literal a), de la Convención Americana sobre Derechos Humanos, precisa que ninguna disposición de la Constitución, la Convención o las leyes deben ser interpretadas en el sentido que permitan al Estado suprimir el goce y ejercicio de los derechos y libertades reconocidas en la Convención o limitarlos en mayor medida que la prevista en ella.

La Convención establece un mínimo de contenido de los derechos que debe ser protegido por los Estados Parte, por lo que las disposiciones de la Convención no pueden ser interpretadas en el sentido de "limitar el goce y ejercicio de cualquier derecho o libertad que pueda estar reconocido de acuerdo con las leyes de cualquiera de los Estados parte o de acuerdo con otra Convención en que sea parte uno de dichos Estados". Ello exige al Estado parte y a sus operadores jurídicos aplicar el principio favor persona of favor homine aplicando la norma que mejor protege u optimiza el derecho fundamental.

A su vez, la $\mathrm{CADH}$, como lo señala el artículo 29, literal c), que constituye norma interpretativa imperativa para los Estados Partes precisa que no se pueden excluir otros derechos y garantías que son inherentes al ser humano o que se derivan de la forma democrática representativa de gobierno".

Esta norma constituye un reconocimiento explícito de la existencia de derechos implícitos, los cuales no pueden ser desconocidos por el solo hecho de no estar establecidos en una norma positiva.

\section{Los derechos como límites del ejercicio de la soberanía y como obligaciones de respeto y promoción por parte de los órganos estatales.}

La Constitución Chilena, reformada en 1989, artículo $5^{\circ}$, inciso $2^{\circ}$, prescribe: "El ejercicio de la soberanía reconoce como limitación el respeto a los derechos esenciales que emanan de la naturaleza humana. Es deber de los órganos del Estado respetar y proveer tales derechos, garantizados por la Constitución, así como por los tratados internacionales ratificados por Chile y que se encuentren vigentes".

Asimismo, el reconocimiento del carácter fundamental de los derechos y su carácter de limitación al ejercicio de la soberanía, genera la obligación de respetar, garantizar y promover los derechos contenidos en las normas de derecho internacional vigentes en la materia, lo que significa la subordinación del Estado a los estándares mínimos previstos por el derecho internacional en la materia.

En el mismo sentido se ha pronunciado la Corte Suprema Chilena, en reiterados y uniformes fallos, de uno de ellos, reproducimos su ratio decidendi:

“TRIGÉSIMONONO: Que, de igual manera, el inciso segundo del artículo $5^{\circ}$ de la 
Constitución Política de la República, preceptúa que el ejercicio de la soberanía se encuentra limitado por "los derechos esenciales de la persona humana" siendo "deber de los órganos del Estado respetar y promover tales derechos garantizados por esta Constitución así como por los tratados internacionales ratificados por Chile que se encuentren vigentes". Valores que son superiores a toda norma que puedan disponer las autoridades del Estado, incluido el propio Poder Constituyente derivado, lo que impide que sean desconocidos (Fallos del Mes $N^{\circ} 446$, sección criminal, página 2.066), aún en virtud de consideraciones de oportunidad en la política social o de razones perentorias de Estado para traspasar esos límites. Otorgándole rango constitucional a los tratados que garantizan el respeto de los derechos humanos, concediéndoles una jerarquía mayor que a los demás tratados internacionales, en cuanto regulan los derechos esenciales que emanan de la naturaleza humana.

"En definitiva los derechos humanos asegurados en un tratado se incorporan al ordenamiento jurídico interno, formando parte de la Constitución material adquiriendo plena vigencia, validez y eficacia jurídica, no pudiendo ningún órgano del Estado desconocerlos y debiendo todos ellos respetarlos y promoverlos, como asimismo, protegerlos a través del conjunto de garantías constitucionales destinadas a asegurar el pleno respeto de los derechos. Esta obligación no sólo deriva del mentado artículo $5^{\circ}$, sino también del $1^{\circ}$, incisos primero y cuarto, y 19, $N^{\circ} 26^{\circ}$, de la Carta Magna y de los mismos tratados internacionales, entre éstos del artículo $1^{\circ}$ común a los Cuatro Convenios de Ginebra, que establece el deber de los Estados Partes de respetar y hacer respetar el derecho internacional humanitario.

Este carácter amplio de protección se desprende de la historia fidedigna del establecimiento del precepto aludido, puesto que su integrante Jaime Guzmán Errázuriz al recalcar que los derechos que arrancan de la naturaleza humana era "el único límite a la soberanía desde un ángulo objetivo, habida consideración que el debe proyectarse conceptualmente con la noción de bien común", de tal suerte que aun cuando esos derechos no estén en el texto constitucional "no por eso una disposición jurídica cualquiera que atentara indebidamente en contra de ellos, dejaría de ser ilegítima” (Actas de la Comisión de Estudios de la Nueva Constitución, sesión 49 de veintisiete de junio de mil novecientos setenta y cuatro)." 10

Como señala uno de los académicos mas reconocidos en la materia, el profesor francés Louis Favoreu, por derechos fundamentales es necesario comprender "el conjunto de los derechos y libertades reconocidos a las personas físicas como a las personas morales (de

10 Sentencia de la Corte Suprema de Justicia, Sala Penal, Rol No 3125 - 04, de fecha 13 de marzo de 2007. Las negritas son nuestras. 
derecho privado o de derecho público) en virtud de la Constitución pero también de los textos internacionales y protegidos tanto contra el poder ejecutivo como contra el poder legislativo por el juez constitucional o el juez internacional"11.

El texto constitucional no permite que el derecho constitucional y el derecho internacional de los derechos humanos sigan siendo considerados en forma compartimentalizada ${ }^{12}$, sino que deben ser abordados como fuentes de un único sistema de protección de los derechos que tiene por fundamento la dignidad de la persona humana, abordándolos en forma integral, realizando una tarea de armonización e integración, eliminando prejuicios y visiones conflictuales, otorgándoles una visión convergente y optimizadora de los derechos fundamentales.

Por bloque constitucional de derechos fundamentales entendemos el conjunto de derechos de la persona ( atributos) asegurados por fuente constitucional o por fuentes del derecho internacional de los derechos humanos (tanto el derecho convencional como el derecho consuetudinario y los principios de ius cogens) y los derechos implicitos, expresamente incorporados a nuestro ordenamiento jurídico por vía del artículo 29 literal c) de la CADH ${ }^{13}$, todos los cuales, en el ordenamiento constitucional chileno, constituyen límites a la soberanía, como lo especifica categóricamente el artículo $5^{\circ}$ inciso segundo de la Constitución Chilena vigente $^{14}$.

El enfoque interpretativo de la Constitución y desde la Constitución, hecho en materia de derechos fundamentales, se complementa con el derecho internacional de los derechos humanos, el que viene de fuera pero se incorpora como fuente de derechos esenciales o fundamentales, complementando los que asegura directamente la Constitución, como lo establece explícitamente en Chile, el artículo $5^{\circ}$ inciso $2^{\circ}$.

El Bloque Constitucional de Derechos Fundamentales que limita la soberanía no es una tabla cerrada, sino que se encuentra abierta al aseguramiento de nuevas exigencias esenciales de la persona humana.

11 Favoreu, Louis. L'élargissement de la saisine du Conseil constitutionnel aux jurisdictions administratives et judiciaires, RFDC N4,1990, págs. 581 y siguientes. Traducción nuestra.

12 Cancado Trindade, Antonio. 1998. Reflexiones sobre la interacción entre el Derecho Internacional y Derecho Interno en la protección de los Derechos Humanos. En AA.VV. V Congreso Iberoamericano de Derecho Constitucional. México, Ed. UNAM, página 109.

13 Dicha disposición establece lo siguiente: “Artículo 29. Normas de interpretación. Ninguna disposición de la presente Convención puede ser interpretada en el sentido de: C) Excluir otros derechos o garantías que son inherentes al ser humano o que se derivan de la forma democrática representativa de gobierno".

14 Sobre esta materia consultar Nogueira Alcalá, Humberto. 2003. Los derechos esenciales o humanos contenidos en los tratados internacionales y su ubicación en el ordenamiento jurídico nacional: doctrina y jurisprudencia. En Revista Ius et Praxis, año $9 \mathrm{~N}^{\circ} 1$, páginas 403 - 466. 
El artículo 29, literal b), de la CADH, exige aplicar al operador jurídico que se encuentra frente a diversas normas de derechos humanos o fundamentales aquella norma que mejor protege los derechos, aplicando la norma interna o la internacional, dependiendo de cual sea aquella que optimice el goce y ejercicio del derecho.

Así puede sostenerse que tanto los derechos fundamentales (atributos) contenidos en las normas constitucionales formales como los contenidos en los tratados internacionales, el derecho consuetudinario internacional y los principios de ius cogens constituyen un bloque en materia de derechos fundamentales de acuerdo con el cual deben ser interpretadas las leyes y demás normas infraconstitucionales.

La Corte Suprema de Justicia chilena ha reconocido que los derechos esenciales contenidos en los tratados constituyen límites al poder estatal, incluido el poder constituyente:

"Que en la historia fidedigna del establecimiento de la norma constitucional del artículo $5^{\circ}$ inciso segundo, queda claramente establecido que la soberanía interna del Estado de Chile reconoce como límite los derechos que emanan de la naturaleza humana; valores que son superiores a toda norma que puedan imponer las autoridades del Estado, incluido el propio Poder Constituyente, lo que impiden sean desconocidos (Fallos del Mes No 446, sección criminal, página 2066, considerando $\left.4^{\circ}\right)^{\prime \prime 15}$.

"Que, como lo ha señalado esta misma Corte suprema en reiteradas sentencias, de la historia fidedigna del establecimiento de la norma fundamental contenida en el artículo $5^{\circ}$ de la Carta Fundamental, queda claramente establecido que la soberanía interna del estado de Chile reconoce su límite en los derechos que emanan de la naturaleza humana, 'valores que son superiores a toda norma que puedan disponer las autoridades del Estado, incluido el propio poder constituyente, lo que impide sean desconocidos' (S.C.S. 30.1.2006)" ${ }^{\prime \prime}$.

Asimismo, los tribunales superiores de justicia chilenos han reconocido jurisprudencialmente la integración de los principios de ius cogens y de derecho consuetudinario internacional, los cuales se incorporan al derecho interno sin ningún acto de formalización:

"Que, en efecto, tal razonamiento parte de la base que el Derecho nacional y el derecho Internacional de los Derechos Humanos es uno solo, por ser un fenómeno que abarca al Derecho en su totalidad, siendo recepcionado dicho derecho internacional de los Derechos

15 Sentencia de la Corte Suprema, Rol No 469-98, de fecha 9 de septiembre de 1998, citado por Cea Egaña, José Luis. Derecho Constitucional Chileno. Tomo I, página 236.

16 Sentencia de la Corte Suprema, Rol N $559-04$, de fecha 13 de diciembre de 2006, considerando $22^{\circ}$. 
Humanos por el Derecho Interno Nacional, tanto como Principio Internacional de los Derechos Humanos, como por los tratados internacionales actualmente vigentes suscritos por Chile. Es así como nuestro ordenamiento jurídico no excluye el procedimiento de incorporación de los Principios Generales del Derecho Internacional de los Derechos Humanos o ius cogens, que pasan a formar parte del derecho interno por su calidad de tales, en tanto los Principios del Derecho Internacional tienen prevalencia sobre éste como categoría de norma de Derecho Internacional General, conforme al acervo dogmático y convencional universal y a la aceptación en la práctica judicial de los tribunales nacionales participes de la Naciones Unidas, además de los tribunales internacionales con jurisdicción respecto a crímenes de lesa humanidad.

“Que, además, los principios internacionales referidos, los convenios, pactos y tratados en que se reconocen los derechos humanos y las garantías a nivel de tribunales nacionales, gozan de primacía constitucional, cuya consecuencias - conforme a una interpretación progresiva y finalista de la Constitución - es que prevalecen sobre la legislación interna, toda vez que se entiende que la prefieren, perfeccionan y complementan. Siendo, por lo mismo, tal normativa invocable por todos los individuos, atendiendo al compromiso moral y jurídico del estado ante la comunidad internacional, de respetarlos, promoverlos y garantizarlos ${ }^{\prime 17}$.

Una reciente sentencia de la Corte Suprema de Justicia de 18 de abril de 2007 reafirma esta concepción, en lo pertinente dicha sentencia sostiene:

"Noveno. Que el artículo $19 N^{\circ} 3$ inciso quinto de la Constitución política del Estado, reconoce a los ciudadanos la igual protección de la ley en el equecicio de sus derechos, en cuanto toda persona puede acceder a la defensa jurídica en la forma que la ley señala y ninguna autoridad o individuo podrá impedir, restringir, o perturbar la debida intervención del letrado si hubiere sido requerida.

$$
[\ldots] \text {. }
$$

Décimo. Que a lo anterior, y conforme a la norma de reenvío contenida en el artículo $5^{\circ}$ de la Constitución, debe extenderse el reconocimiento con rango constitucional del derecho a la defensa, también a los derechos garantizados por los tratados internacionales ratificados por Chile y que se encuentren vigentes, como son [...]" 18 .

\footnotetext{
17 Sentencia de la Corte de Apelaciones de Santiago, Rol N¹46-2006, de fecha 31 de julio de 2006, considerandos $5^{\circ}$ y $6^{\circ}$. Revista Gaceta Jurídica N³13, Julio 2006, Ed. Lexis Nexis, Santiago, 2006, pp. 243 - 254. Las negritas son nuestras.

18 Sentencia de la Corte Suprema de Justicia, Rol N 4.183-06, de fecha 18 de abril de 2007. Revista Gaceta Jurídica. N³22, Editorial Lexis Nexos, Santiago, Abril de 2007, pp. 218 - 222, considerandos noveno y décimo.
} 
El bloque de derechos fundamentales queda configurado así por:

a) Los que la Carta Fundamental explicita sin taxatividad;

b) Los que asegura el derecho internacional a través de los principios de ius cogens ${ }^{19}$; los que asegura el derecho convencional internacional de derechos humanos y derecho internacional humanitario ${ }^{20} \mathrm{y}$ los que asegura el derecho internacional consuetudinario.

La Corte Suprema de Justicia chilena lo ha explicitado en jurisprudencia reciente:

“TRIGÉSIMO PRIMERO: Que la indicada consagración del derecho de gentes y su aceptación permite considerar que existía a la época del hecho criminoso de autos, un sistema de protección de derechos obligatorio para el Estado de Chile, independientemente del consentimiento expreso de las naciones vinculadas y que se conoce como reglas imperativas de derecho internacional o "ius cogens". Tales patrones se imponen a los Estados y prohiben los crímenes de lesa humanidad, incluso durante el desarrollo de conflictos de carácter internacional o internos. Este derecho perentorio internacional implica el rechazo "in limine" por las naciones civilizadas de injustos que repugnan a la conciencia humana y que constituyen crimenes contra la humanidad.

Dichas disposiciones conforman el derecho internacional preceptivo el cual junto con el derecho internacional convencional, forman parte integrante del derecho chileno.

TRIGÉSIMO SEGUNDO: Que esta normativa deriva de conceptos jurídicos antiguos de un orden superior que las leyes del hombre y de las naciones no pueden contravenir habiendo sido aceptadas, sea expresamente por tratados o tácitamente por la costumbre, para proteger la moral pública en ellas contenidas. Su principal característica distintiva es su relativa indelebilidad, ya que son reglas de derecho consuetudinario internacional que no pueden soslayarse por tratados o voluntad, sino por la formación de una posterior disposición consuetudinaria de efecto contrario. La contravención de estos preceptos afecta gravemente la conciencia moral de la humanidad y obliga, a diferencia del derecho

19 Ellos han sido incorporados al derecho interno mediante la Convención de Viena sobre Derecho de los Tratados, ratificada por Chile y vigente desde 1981, cuyo artículo 53 determina: "una norma imperativa de derecho internacional general es una norma aceptada y reconocida por la comunidad internacional de Estados en su conjunto como norma que no admite acuerdo en contrario y que sólo puede ser modificada por una norma ulterior de derecho internacional general que tenga el mismo carácter".

20 La Convención de Viena establece en el artículo 26: "Todo tratado en vigor obliga a las partes y debe ser cumplido por ellas de buena fe", y en el artículo 27: "Una parte no podrá invocar las disposiciones de su derecho interno como justificación del incumplimiento de un tratado.". 
consuetudinario tradicional, a la comunidad internacional como un todo, independientemente de su rechazo, reconocimiento o aquiescencia.

El referido carácter obligatorio de los cánones de ius cogens concluyó con su transformación en derecho convencional por obra de la Convención de Viena sobre el Derecho de los Tratados de mil novecientos sesenta y nueve, ratificada por Chile el nueve de mayo de mil novecientos ochenta y uno, la que dispone en su artículo 53 que "es nulo todo tratado que, en el momento de su celebración, esté en oposición con una norma imperativa de derecho internacional general. Para los efectos de la presente Convención, una norma imperativa de derecho internacional general es una norma aceptada y reconocida por la comunidad internacional de Estados en su conjunto como norma que no admite acuerdo en contrario y que solo puede ser modificada por una norma ulterior de derecho internacional general que tenga el mismo carácter". Es así como la doctrina las ha conceptualizado como aquellos dogmas o principios estructurales del orden internacional reflejo de valores fundamentales generalmente aceptados por la comunidad internacional que, en virtud de su carácter dominante, obligan a todos los Estados con independencia de su voluntad (Antonio Cassese: "Los derechos humanos en el mundo contemporáneo", Ariel, Barcelona, primera reimpresión, año mil novecientos noventa y tres, página 241).

Las reglas ius cogens no son exclusivamente meros criterios directivos, ni juicios de valor simplemente, ni escuetos dictados de la razón, son auténticas normas jurídicas en sentido sustancial, pues suministran pautas o modelos de conducta. Existen con independencia de su formulación y cuando las leyes las recogen, o sea, las expresan en su fórmula, no quiere decir que se esté mudando su naturaleza verdaderamente jurídica, la cual, en definitiva, es independiente y autónoma de su consagración a nivel positivo.

Por lo tanto, las máximas de ius cogens son disposiciones a partir de las cuales surgen obligaciones erga omnes, las que no pueden ser dejadas sin efecto o modificadas por un acuerdo entre Estados sino únicamente por una norma posterior que, al mismo tiempo, ostente el carácter de imperiosa.

TRIGÉSIMO TERCERO: Que si bien es cierto que una de las más severas críticas que se plantean en contra de la noción de ius cogens es la vaguedad e indefinición de aquellas que la componen, no lo es menos que existen un conjunto de preceptos cuya determinación como tal no presenta discusión llamado "núcleo duro de normas de ius cogens de derechos humanos", inderogables bajo cualquier circunstancia o excepción que generan obligaciones erga omnes (Carlos Villán Durán: "Curso de Derecho Internacional de los Derechos Humanos", Editorial Trotta, Madrid, año dos mil dos, página 102), dentro del cual encontramos disposiciones tales como la prohibición de la agresión o el uso de la fuerza en las relaciones internacionales; la prohibición del genocidio, la esclavitud, la discriminación racial y de las ejecuciones sumarias o extralegales; así como la prohibición de la tortura. No parece 
que nadie-incluso sin ser letrado-podrá dudar que los principios enunciados no derivan su carácter propiamente jurídico de la circunstancia meramente accidental de haber sido expresados en una determinada ley positiva.

Precisamente, ya en mil novecientos setenta y uno Roberto Ago consideraba que las reglas de ius cogens incluian "las normas fundamentales relativas a la salvaguardia de la paz, y particularmente las que prohíben el recurso a la fuerza o la amenaza de fuerza; las normas fundamentales de carácter humanitario: prohibición del genocidio, la esclavitud y la discriminación racial, protección de los derechos fundamentales de la persona humana en tiempo de paz y de guerra" (citado por Vicente Chetail: "La contribución de la Corte Internacional de Justicia al Derecho Internacional Humanitario”, en Revista Internacional de la Cruz Roja, número 805, año dos mil tres, páginas 235 a 269). ”21

La misma sentencia de la Corte Suprema se refiere a la incorporación automática del derecho consuetudinario internacional:

“TRIGÉSIMO SEXTO: Que al respecto esta Corte ha reconocido en variadas oportunidades que los principios del derecho internacional y las normas del derecho consuetudinario forman parte del ordenamiento jurídico chileno con primacía sobre las leyes internas. En efecto, en el caso denominado Lauritzen con Fisco este tribunal sostuvo "que aún en el supuesto de que pudieren tener aplicación las leyes internas, los principios del Derecho Internacional tienen prevalencia en estos casos” (Revista de Derecho y Jurisprudencia, Tomo LVI, segunda parte, sección cuarta, página 66).

Igualmente, se ha declarado que el derecho internacional, aun consuetudinario, tiene prevalencia sobre la legislación nacional, a pesar que el primero no se encuentre traducido en tratados o convenciones obligatorias para Chile, sino solamente en los principios de derecho internacional generalmente aceptados, lo que se entienden automáticamente incorporados en el derecho chileno, sin necesidad de un acto de recepción por parte de los órganos del Estado. Afirmando que es inaceptable en derecho que un tratado internacional pueda ser modificado por un acto unilateral de uno de los contratantes (Revista de Derecho y Jurisprudencia, tomo LII, segunda parte, sección primera, página 478; Revista Fallos del Mes, septiembre de mil novecientos sesenta y nueve, páginas 223 a 224 y junio de mil novecientos setenta y cinco, página 90 y Alfredo Etcheberry O.: "El Derecho Penal en la Jurisprudencia”, tomo I, Parte General, Editorial Jurídica de Chile, reimpresión de la segunda edición, Santiago, Chile, año dos mil dos, páginas 38 y 39).

21 Sentencia de la Corte Suprema de Justicia, Sala Penal, Rol No 3125 - 04, de fecha 13 de marzo de 2007 , considerandos $31-33$. 
Del mismo modo, la doctrina autorizada asevera que cuando se presenta un posible conflicto con el derecho internacional, sea convencional o consuetudinario, el juez tiene en primer término la regla externa, toda vez que no es de presumir que el legislador nacional haya querido infringir el derecho internacional. (Adolfo Veloso: "Algunos problemas acerca de las relaciones entre el derecho internacional y el derecho chileno”, en Revista de Derecho de la Universidad de Concepción, $N^{\circ} 165$, enero - diciembre de mil novecientos setenta y siete, página 272 y Santiago Benadava: “Derecho Internacional Público”, Editorial Jurídica de Chile, segunda edición, año mil novecientos ochenta y dos, página 13). También la primacía de los Principios Generales del Derecho Internacional ha sido reconocida desde los albores de nuestra República, así la Lei de Garantías Individuales, de veinticinco de septiembre de mil ochocientos ochenta y cuatro, Título Primero, que trata De las Restricciones a la Libertad Individual en Jeneral refiere en su artículo $5^{\circ}$ : las disposiciones contenidas en los tres articulos precedentes no se aplican: $2^{\circ} \mathrm{A}$ los que se dictaren en conformidad a tratados celebrados con naciones extranjeras o a los principios jenerales de derecho internacional, como, por ejemplo, en el caso de extradición de criminales $i$ de aprehensión de marineros desertores (Pedro Javier Fernández: "Código Penal de la República de Chile, Explicado y Concordado", Imprenta Barcelona, segunda edición, Santiago, Chile, año mil ochocientos noventa y nueve, página 426). En el mismo sentido Manuel Egidio Ballesteros sostiene "y con ser sólo un cuerpo de doctrinas, el derecho internacional es sin embargo, de aplicación preferente a las leyes positivas de carácter interno, en aquellas cuestiones regidas por él" (Manuel Egidio Ballesteros: "La Ley de Organización y Atribuciones de los Tribunales en Chile", tomo I, Santiago, Chile, año mil ochocientos noventa, página 571).

El gobierno chileno ha tomado la misma posición tanto en lo atinente al derecho internacional convencional como del consuetudinario. Así, la Asesoría Jurídica del Ministerio de Relaciones Exteriores, por ejemplo, en el caso en que un Tribunal de Menores habia decretado orden de arraigo por dos muchachos que se encontraban, junto a su madre, asilados en una embajada con posterioridad al pronunciamiento militar de septiembre de mil novecientos setenta y tres, al considerar que: "por sobre la resolución judicial emanada del referido tribunal de menores corresponde aplicar las normas de Derecho Internacional que gobiernan la institución del asilo”. (Informe $N^{\circ} 96$ de la Asesoría Jurídica del Ministerio de Relaciones Exteriores de Chile, de catorce de noviembre de mil novecientos setenta y tres, citado en Hugo Llanos Mansilla: "Teoría y Práctica del Derecho Internacional Público", Tomo III, Editorial Jurídica de Chile, Santiago, mil novecientos ochenta y tres, páginas 408 a 410). "22.

22 Sentencia de la Corte Suprema de Justicia, Sala Penal, Rol No 3125 - 04, de fecha 13 de marzo de 2007, considerando $36^{\circ}$. Las negritas son nuestras. 
Otro fallo de la Corte Suprema de diciembre de 2006, sostiene la misma tesis:

220.- Que, como lo ha señalado esta misma Corte Suprema en reiteradas sentencias, de la historia fidedigna del establecimiento de la norma constitucional contenida en el artículo $5^{\circ}$ de la Carta Fundamental, queda claramente establecido que la soberanía interna del Estado de Chile reconoce su límite en los derechos que emanan de la naturaleza humana, «valores que son superiores a toda norma que puedan disponer las autoridades del Estado, incluido el propio Poder Constituyente, lo que impide sean desconocidos» (S.C.S., 30.01.1.996).

$23^{\circ}$.- Que la jurisprudencia y doctrina nacionales, desde muy antiguo, han reconocido la prevalencia del Derecho Internacional, en el supuesto de contradecir éste el derecho interno. Valga, en apoyo de este aserto, la referencia a las sentencias «Lauritzen con Fisco» o de los barcos daneses (R.D.J., T.52, II, $1^{a}$, p. 485 y ss.); el fallo recaído en un caso sobre extradición activa, en que se explicitó que los principios de Derecho Internacional "priman siempre sobre los preceptos del derecho interno del Estado» (en: R.D.J., T. 56, II, 4, pág. 66); los casos Embajada de la República de China, de 1.969 (F.M. septiembre de 1.969, págs. 223 y 224) y Embajada de Cuba, de 1.975 (F.M. junio de 1.975, pág. 90) y, en jurisprudencia posterior a los hechos de autos - pero demostrativa de la continuidad del principio que interesa - las sentencias de 26.10.95 (Rol $N^{o} 5.566$ ), consid. $14^{\circ}$ y 9.09.98 (Rol $N^{o}$ 469/98), consid. $10^{\circ}$, todas de esta Corte Suprema.

Y para demostrar la amplia recepción de esta misma tesis, en la doctrina nacional clásica, recordemos que ya don Manuel E. Ballesteros, a fines del siglo XIX, sostenía que «con sólo ser un cuerpo de doctrinas, el Derecho Internacional es, sin embargo, de aplicación preferente a las leyes positivas de carácter interno, en aquéllas cuestiones regidas por él»» (La Ley de Organización y Atribuciones de los Tribunales, T.I, Stgo, 1.890, pág. 571).

Por cierto, los internacionalistas chilenos contemporáneos «Llanos, Benadava, Bustos Valderrama, Nogueira, C. Medina, entre muchos otros- participan plenamente de esta posición" 23 .

En tal virtud, las reglas del derecho internacional generalmente aceptadas se entienden automática y globalmente incorporadas en el derecho interno, y deben ser aplicadas por los tribunales nacionales con preferencia al derecho interno. Primacía de las normas internacionales de Derecho Internacional General que determina que, en los delitos de lesa humanidad, dichas disposiciones actualmente recepcionadas constitucionalmente vía tratado internacional y

23 Sentencia de la Corte Suprema de justicia, Sala Penal, Rol N 559-04, de fecha 13 de diciembre de 2006, considerandos $22-24$. 
vinculantes desde antes como Principio General del Derecho Internacional de los Derechos Humanos, son obligatorias en la forma precedente.

c) Los derechos esenciales implícitos que puedan desarrollarse en el futuro, respecto de lo cuales no hay reconocimiento aún a través de las diversas fuentes del derecho interno o internacional.

La interpretación integradora de la Constitución implica que el juez presta atención a los derechos explícitos, a los valores, principios, fines y razones_históricas del ordenamiento constitucional, completando y dando plenitud al sistema de derechos.

A su vez, el carácter esencialmente abierto de las normas que configuran abstractamente los derechos esenciales de la persona, llevan a desarrollar una interpretación de la Carta Fundamental y de todo el ordenamiento jurídico sobre el que ella actúa, en el sentido de que permita obtener para los derechos, el mayor grado de protección y efectividad, entendidos desde una perspectiva democrática.

La confluencia e integración en el sistema jurídico de los derechos, reconocidos por vía de fuente interna y de fuente internacional, obliga a unificar el criterio de interpretación del sistema de derechos humanos, dando coherencia a dicho sistema.

Esta visión interpretativa convergente de los derechos, los asegurados por la Constitución y los asegurados por el derecho convencional internacional, deriva necesariamente del artículo quinto inciso segundo de la Carta Fundamental. De esta manera, el sistema de derechos tiene la fuerza para ser interpretado de la forma más adecuada a su optimización.

Las fuentes internas y las fuentes internacionales de derechos se retroalimentan, las interpretaciones reduccionistas van en contra del sentido y finalidad del sistema de derechos esenciales fijado por la Carta Fundamental, que es lograr la optimización y plenitud del sistema, acogiendo el ámbito que más enriquece y garantiza el ejercicio de los derechos, éste es el deber ser existencial del Derecho como diría Cossio.

Todas las normas sobre derechos fundamentales contenidas en nuestro ordenamiento jurídico deben ser interpretadas armónicamente con las respectivas fuentes normativas de derecho interno como las fuentes convencionales internacionales (que son, a la vez, derecho interno, ya que se han incorporado tales derechos por mandato del constituyente originario a nuestro orden jurídico, constituyendo límites a la soberanía), con las claves hermenéuticas del Derecho de los Derechos Humanos y sus órganos de aplicación, en especial, en el ámbito regional americano, por la Corte Interamericana de Derechos Humanos.

\section{El Derecho Internacional de los Derechos Humanos es fuente del Derecho Interno cuando}


contiene elementos que enriquecen al Derecho Interno, cuando agregan un "plus" al contenido normativo de los derechos delimitados y configurados en el derecho interno $y$ viceversa, el sistema nacional de Derecho enriquece al Derecho Internacional de derechos humanos, buscando siempre la integralidad maximizadora del sistema de derechos esenciales o humanos, todo lo que está reconocido en el artículo 29 de la Convención Americana de Derecho Humanos y en el artículo $5^{\circ}$ del Pacto Internacional de Derechos Civiles y Políticos de Naciones Unidas.

El intérprete constitucional debe entender que existe una retroalimentación recíproca entre fuente interna y fuente internacional recepcionada internamente en materia de derechos fundamentales. En la misma perspectiva debe existir una retroalimentación entre el intérprete final del derecho interno y el intérprete final del derecho regional o internacional de derechos humanos, especialmente, de aquel que el Estado se ha comprometido a respetar y garantizar ante la comunidad internacional.

Así lo entiende también Cea Egaña, para el cual, "En virtud del artículo $5^{\circ}$ inciso $2^{\circ}$, modificado en 1989, la Constitución hace parte formal y sustantiva de su texto los derechos, deberes, acciones y recursos contemplados en los tratados internacionales ratificados por Chile y vigentes en nuestro país que versen sobre los atributos esenciales de la persona humana.

"Existe complementación, y no oposición, por ende, entre el Estatuto de la Persona en el derecho interno y en el derecho supranacional. Consecuentemente también, se ha vigorizado aquel estatuto por la conjugación o armonía de ambos sistemas jurídicos. Trátese de una evidencia más acerca de la nueva concepción de la soberanía, limitada y limitable por el respeto que debe al ejercicio de aquellos derechos" 24 .

Asimismo, si existe el postulado de la interpretación de las normas infraconstitucionales de conformidad con la Constitución y la Carta Fundamental como lo determina el artículo $6^{\circ}$ inciso primero de la Constitución, el cual precisa que "los órganos del Estado deben someter su acción a la Constitución y a las normas dictadas de conformidad con ella", implica que los derechos fundamentales contenidos en la Constitución formal y en los tratados internacionales limitan la soberanía como lo determina el artículo $5^{\circ}$ inciso $2^{\circ}$, de manera tal que este bloque constitucional de derechos constituye un parámetro conformador de la interpretación conforme

24 Cea Egaña, José Luis. 2002. Derecho constitucional chileno. Tomo I. Santiago, Ed. Universidad Católica de Chile, pág. 113. 
a la Constitución, por lo que todas las normas infraconstitucionales deben interpretarse y aplicarse conforme al bloque constitucional de derechos fundamentales ${ }^{25}$.

Este fundamento es el que justifica referirse a un Bloque constitucional de derechos fundamentales, ya que son los derechos fundamentales como atributos de la persona humana, independientemente de la fuente interna o internacional en la que se hayan asegurado, los que constituyen el parámetro de control de constitucionalidad en materia de normas internas infraconstitucionales.

Los derechos esenciales, fundamentales o humanos, según el nomen iuris que quiera utilizarse, y sus diversos atributos reconocidos por fuente nacional o internacional, constituyen en nuestro ordenamiento jurídico límites a la soberanía, por tanto límites a la potestad constituyente derivada, legislativa, administrativa y jurisdiccional. Lo que implica en definitiva, que tales derechos y sus atributos asegurados y garantizados por fuente interna o internacional, forman parte necesariamente del parámetro de control de constitucionalidad, en cuanto límites de la soberanía, que debe asumir el Tribunal Constitucional, al controlar los actos y normas emanados de los poderes constituidos.

Las Cartas Fundamentales exigen a los agentes y órganos del Estado no solo una función de respeto de los derechos, sino también una función promocional, debiendo promover condiciones más humanas de vida y removiendo obstáculos para hacer efectivas la dignidad de la persona, la libertad y la igualdad, con miras a la plenitud del ejercicio de los derechos; función promocional reconocida, explícitamente, en nuestra Constitución chilena, en el artículo $5^{\circ}$ inciso segundo ${ }^{26}$.

La Constitución exige a todos los operadores jurídicos y, en especial, a los órganos de jurisdicción constitucional dentro sus competencias, remover los obstáculos que posibiliten el libre y pleno ejercicio de los derechos como asimismo maximizar el plexo de derechos y garantías de la persona humana.

25 En la misma perspectiva, el Comisionado Jaime Guzmán en la Comisión de Estudios de la Nueva Constitución, en sesión $101^{\text {a }}$ de fecha 9 de enero de 1975 , señalaba “...ese texto (refiriéndose al inciso $2^{\circ}$ del artículo $5^{\circ}$ ) autoriza entablar incluso recursos de inaplicabilidad y a pedir la inconstitucionalidad de leyes que aunque no violenten algún texto expreso de la Constitución, violenten derechos fundamentales de la persona humana, porque al hacerlo están violentando el texto expreso de la Constitución: el que señala que la soberanía está limitada por los derechos fundamentales o naturales del hombre" (pág. 12).

26 El artículo $5^{\circ}$, inciso $2^{\circ}$, segunda oración, precisa: "Es deber de los órganos del Estado respetar y promover tales derechos, garantizados por esta Constitución, así como por los tratados internacionales ratificados por Chile y que se encuentran vigentes" (las cursivas son nuestras). 
El deber de promover los derechos también se concreta a través de una adecuada interpretación de ellos, ya que los derechos no son las normas, por tanto, cuando faltan normas debe producirse la integración para suplir la falta de reconocimiento normonológico y no afirmar que porque no hay norma no hay derecho. El operador jurídico debe tener la flexibilidad de buscar una solución acorde con el espíritu del sistema de derechos, de acuerdo con su objeto y su finalidad, teniendo en consideración el contexto y la razón histórica, como asimismo, los valores que explicita el sistema jurídico. Ello implica negar la posición reduccionista para la protección de la persona y de sus derechos esenciales.

Nada impide, en una perspectiva técnico jurídica, la introducción de garantías de los derechos esenciales o humanos por vía de normas de derecho interno o provenientes del derecho internacional que constituyan un "plus" respecto de las normas vigentes, ya que ello cumple la finalidad de asegurar y de promover tales derechos que es un deber constitucional de todos los órganos y agentes estatales. La introducción de normas que mejoren el contenido de derechos y sus garantías no pueden ser consideradas inconstitucionales, si se aplican las reglas interpretativas "favor homine" o "favor persona" y se tiene presente el desarrollo progresivo de los derechos.

Los valores, principios y fines del capítulo de Bases de la Institucionalidad, en materia de derechos, son preceptos constitucionales directamente aplicables, a la luz de los cuales debe interpretarse todo el resto de la normativa constitucional y del ordenamiento jurídico, como lo ha explicitado el Tribunal Constitucional.

La labor interpretativa constitucional requiere de una reconstrucción de todo el contenido que establece el complejo normativo de la Constitución, la lectura e interpretación de todo precepto de la Carta Fundamental debe ser hecho en su contexto, teniendo en consideración los principios, valores, fines y razón histórica del ordenamiento constitucional, lo que le da al Juez Constitucional, un espacio significativo de movilidad interpretativa e integradora que convierte al juez en un protagonista activo y creador, que realiza la mediación entre la Constitución y la situación específica.

En materia de derechos humanos, habrá sólo interpretación cuando se señale que fuera de las normas no hay otros derechos, mientras que además de interpretación habrá integración, cuando consideremos que fuera de las normas sobre derechos, hay derechos que carecen de normas.

Es posible «proponer que cuando faltan normas sobre derechos y quien detecta esa ausencia o laguna normativa cree o valora que, pese al vacío normativo, hay derechos no formulados, la carencia se debe colmar a través de la integración, para cuya efectividad 
también es menester «interpretar» (encontrar el sentido) del sistema completo de derechos, en el que algunos constan en normas y otros carecen de ellas» ${ }^{27}$.

\section{Algunas consideraciones sobre la aplicación de la media prescripción a autores de delitos contra la humanidad y contra los derechos humanos dictadas por la Corte Suprema de Justicia.}

El secuestro calificado es un delito permanente cuya consumación se mantiene mientras la persona no recupere su libertad o se determine su muerte. Dicho delito es el equivalente al de desaparición forzada de personas como crimen de lesa humanidad o crimen contra los derechos humanos, el cual forma parte del derecho consuetudinario y convencional internacional, además de principio de ius cogens, como lo ha precisado tanto la jurisprudencia de la Corte Interamericana de Derechos Humanos, como la propias sentencias de la Corte Suprema de Justicia, en reiterados fallos uniformes ${ }^{28}$.

Tal secuestro constituye tanto un crimen de lesa humanidad como un crimen contra los derechos humanos, crímenes que el derecho internacional vigente, válido y aplicable en Chile, determina que por su naturaleza y gravedad no le son aplicables la amnistía, la prescripción ni otros eximentes o aminorantes de responsabilidad ${ }^{29}$.

El tema que hoy nos ocupa y preocupa es que la Sala Penal de la Corte Suprema, después de asumir la jurisprudencia de la Corte Interamericana emanada del caso Almonacid Arellano y otros vs. Chile, en sentencias inauguradas con el "caso Molco" en diciembre de $2006^{30}$ y desarrollada en el "caso Chena" en marzo de $2007^{31}$ y seguidas por otras similares, en los cuales se asume que los crímenes como el secuestro calificado y el homicidio desarrollado por agentes del Estado en ejecución de una política estatal emanada del régimen autoritario militar, constituyen crímenes de lesa humanidad, los cuales son inamnistiables e imprescriptibles ${ }^{32}$, de

27 Bidart Campos, Germán, La interpretación del sistema de derechos humanos, Ed. Ediar, Buenos Aires, Argentina, 1994 p. 58. En el caso chileno, ello ha sido aceptado por el Tribunal Constitucional, en su sentencia rol $\mathrm{N}^{\circ} 22$ de 1995, en el que reconoció que si bien el texto literal constitucional del derecho a la libertad de información (art. $19 \mathrm{~N}^{\circ} 12$ ) no lo contempla, el derecho a ser informado es un derecho constitucional. Asimismo, la jurisprudencia de los tribunales superiores ordinarios (Cortes de Apelaciones y Corte Suprema) en diversos fallos han reconocido el derecho a la propia imagen pese a no estar consignado en el texto constitucional como derecho fundamental.

28 Por todos, Sentencia de la Corte Suprema de Justicia, Caso Molco, Rol N ${ }^{\circ}$ 559-04, de trece de diciembre de dos mil seis, Sentencia de la Corte Suprema de Justicia, Caso Chena, de trece de marzo de dos mil siete.

29 Sentencia Corte Suprema de Justicia, Rol No 2666-04, casación Matías Ñanco.

30 Sentencia de la Corte Suprema de Justicia, Caso Molco, Rol № 559-04, de trece de diciembre de dos mil seis.

31 Sentencia de la Corte Suprema de Justicia, Caso Chena, de trece de marzo de dos mil siete.

32 Sentencia Corte Suprema de Justicia, Rol N 3125 - 04, considerando Vigésimo sexto y ss.; ya en Rol No 2666-04, precisa en su considerando $17^{\circ}$ que "la Convención sobre la Imprescriptibilidad de los Crímenes de Guerra y de los Crímenes de Lesa Humanidad de 1968, que aunque no ha sido ratificada por Chile, surge en la actualidad con categoría de norma de ius cogens o principios generales del derecho internacional". 
acuerdo con las normas del derecho internacional consuetudinario y los principios imperativos del derecho internacional (ius cogens), los cuales se incorporan directa e inmediatamente al ordenamiento jurídico chileno, además del derecho convencional internacional que los prevén expresamente, lo que constituyó un avance significativo a favor del pleno respeto y garantía jurisdiccional de los derechos de las víctimas y sus familias a una tutela judicial efectiva dentro de un debido proceso, ha empezado a dictar sentencias que constituyen un retroceso en la materia, y que son incoherentes con sus propias sentencias antes mencionadas, al aplicar, en diversos casos, entre ellos el "caso Rivera Matus" "33 "caso Contreras Maluje" ", "caso Parral" 35 , la media prescripción, en beneficio de los autores de tan graves crímenes contra la humanidad y contra los derechos humanos, generando una conducta que podría constituir una vulneración de derechos humanos por resoluciones judiciales, como analizaremos a continuación.

Los delitos contra la humanidad como son las desapariciones forzadas o secuestros calificados, son inamnistiables e imprescriptibles como lo ha determinado la Corte Suprema ${ }^{36}$. Si tales delitos de lesa humanidad son imprescriptibles, cabe preguntarse sobre el sentido y alcance de la aplicación de la media prescripción, cuando ella es aplicable sólo a delitos comunes que son los considerados en el Código Penal, como por razones obvias sólo a aquellos delitos que son susceptibles de prescribir según su naturaleza, lo que desde ya puede señalarse que no es aplicable a los crímenes contra la humanidad y contra los derechos humanos, como ha determinado la propia Sala Penal de la Corte Suprema en su jurisprudencia de los últimos dos años. Si no procede aplicar la prescripción por ser tales delitos imprescriptibles, tampoco puede aplicarse la media prescripción, que constituye una especie de aplicación parcial de la primera. No pueden aplicarse instituciones diseñadas para delitos comunes a crímenes de lesa humanidad y contra los derechos humanos, ya que ellos constituyen un tipo especial, al cual no se le aplican las reglas comunes y se rigen por el derecho internacional.

Por otra parte, al ser aplicable la prescripción sólo a delitos comunes (los crímenes de lesa humanidad no lo son), si no se prueba en el transcurso de la investigación la fecha en que la víctima recupera su libertad o la fecha de su muerte, no es posible establecer el momento desde el cual se debe establecer el computo del plazo para la prescripción, como nos ha señalado en sus sentencias la propia Corte Suprema ${ }^{37}$, porque no hay fecha desde la cual pueda determinarse

33 Sentencia de la Corte Suprema, Caso Rivera Matus, Rol N³808-06, de treinta de julio de dos mil siete.

34 Sentencia de la Corte Suprema de Justicia, "Caso Contreras Maluje”, Rol No 6188-06, de trece de noviembre de dos mil siete.

35 Sentencia de la Corte Suprema de Justicia, Rol N³.587-2005, de 27 de diciembre de 2007.

36 Sentencia de la Corte Suprema, Rol No 3452 - 06, de diez de mayo de dos mil siete, considerando quincuagésimo cuarto.

37 Sentencia de la Corte Suprema, Rol N³215-05, de 30 de mayo de 2006. 
el cómputo de la mitad del tiempo que corresponde a la prescripción, cuya determinación requeriría tener pruebas del término del secuestro o de la fecha de muerte de la víctima, de lo contrario, como la propia Corte Suprema ha fallado, tales secuestros calificados son de consumación permanente, además de ser delitos imprescriptibles.

El plazo establecido por el legislador para calificar el delito de secuestro por el art. 141 del Código Penal, (de noventa días, hoy es de quince días) para estimar como mas grave la conducta delictiva, no puede utilizarse para contabilizar el plazo como un inicio de la consumación del delito con el objeto o finalidad de considerar una atenuante favorable al autor del crimen de lesa humanidad, por lo que considerar dicho plazo, para de allí considerar el plazo de la prescripción no tiene en consideración ni el contexto ni la finalidad con la que fue dictada dicha disposición, además de ser contradictorio con el tipo penal, como por lo demás lo han señalado algunos de los ministros integrantes de la misma Sala Penal de la Corte Suprema.

La Sala Penal de la Corte Suprema aplica a un delito que su propia jurisprudencia considera de carácter permanente e imprescriptible por ser de lesa humanidad y contra los derechos humanos en cuanto crimen atroz que violenta al conjunto de la humanidad, un plazo de consumación previsto como una determinante de agravamiento de responsabilidad para un delito común en el Código Penal, respecto del cual eventualmente podría aplicarse la prescripción o la media prescripción, lo que deja perplejo a cualquier observador imparcial.

Es necesario recordar en esta materia que la Corte Suprema como órgano del Estado chileno está vinculada por el artículo1.1 de la Convención Americana de Derechos Humanos, que determina imperativamente la obligación de respetar y garantizar el libre y pleno ejercicio de los derechos humanos o fundamentales reconocidos en ella. Sobre la obligación de garantía la jurisprudencia uniforme y sostenida de la Corte Interamericana, como órgano jurisdiccional vinculante e intérprete supremo de la Convención, ha determinado que ello implica investigar, perseguir y sancionar efectiva y proporcionalmente a los responsables de graves violaciones de derechos humanos que constituyen crimenes de lesa humanidad. La Corte Interamericana de Derechos Humanos ha determinado que: "El acceso a la justicia constituye una norma imperativa de Derecho Internacional y, como tal, genera obligaciones erga omnes para los Estados de adoptar las medidas que sean necesarias para no dejar en la impunidad esas violaciones, ya sea ejerciendo su jurisdicción para aplicar su derecho interno y el derecho internacional para juzgar y, en su caso, sancionar a los responsables, o colaborando con otros Estados que lo hagan o procuren hacerlo" 38 .

38 CIDH. Caso Goiburú y otros Vs. Paraguay, sentencia de 22 de septiembre de 2006, Serie C No. 153, párrafo 131. 
La sanción debe tener el carácter de seria, eficaz, proporcional al crimen cometido (crimen contra la humanidad el cual ha privado de libertad, que ha afectado la integridad y ha constituido en definitiva el asesinato de un a persona) y pertinente a tal fin, garantizando los derechos de las víctimas y sus familiares.

La imprescriptibilidad de los crimenes de lesa humanidad es hoy norma imperativa de derecho internacional o ius cogens, declarado así jurisdiccionalmente por los órganos competentes para ello, lo que la Corte Suprema en su Sala Penal ha asumido a través de sus sentencias, de buena fe y cumpliendo con sus obligaciones internacionales como órgano del Estado de Chile en algunas de sus sentencias ${ }^{39}$.

Mediante la determinación de la imprescriptibilidad de los crímenes de lesa humanidad la comunidad mundial busca que tales crímenes no sean olvidados y que el transcurso del tiempo no afecte sus posibilidades de sanción como ocurre en todas parte del planeta, respecto de los cuales no puede aplicarse la prescripción que es el transcurso del tiempo que lleva al olvido de la responsabilidad en la concreción del delito, ni tampoco la media prescripción que es una especie de prescripción, que corresponde a la misma naturaleza de la primera y que implica aplicar la dimensión temporal a un delito que por definición no se le puede aplicar dicha variable de tiempo y que tiene los mismos objetivos de seguridad objetiva, que el ius cogens niega a los crímenes de lesa humanidad. Los crímenes contra la humanidad son crímenes diferentes a los delitos comunes, donde el transcurso del tiempo no produce efecto alguno, donde el reproche social de la humanidad no disminuye con el transcurso del tiempo, el cual se mantiene con carácter permanente, la humanidad busca que el crimen no sea olvidado y el criminal castigado efectivamente, no importando el momento en que ello ocurra, a diferencia de lo que acontece con los delitos comunes y el reproche social de ellos, en la medida en que tales delitos son susceptibles de prescripción y la variable tiempo es un elemento que debe considerarse, rigiendo las instituciones de la prescripción y la media prescripción.

La Corte Suprema en su Sala Penal al aplicar la media prescripción a un crimen de lesa humanidad está desconociendo la obligación de sancionar proporcionadamente dicho crimen de lesa humanidad y de afectar el principio imperativo de derecho internacional de la imprescriptibilidad, vale decir, que el transcurso del tiempo desde el delito no tenga ninguna consideración respecto de la acción penal ni respecto de la sanción del criminal, ya que la media prescripción está referida directamente a la prescripción y es una especia disminuida de ella, que parte de la consideración del transcurso del tiempo y que en virtud del lapso transcurrido beneficia al autor del delito. 
Por otra parte, la media prescripción como institución de derecho interno sólo es aplicable a los delitos comunes respecto de los cuales los procesados (en el contexto del proceso penal antiguo) se presenten o fueren habidos durante el proceso y no en el caso de que ellos estén presentes durante todo el proceso penal.

La aplicación de la media prescripción a crímenes contra la humanidad y contra los derechos humanos que son por naturaleza imprescriptibles, implica a su vez, la aplicación de una pena no proporcionada al crimen cometido y la sanción constituye solo una apariencia de justicia, que deja a los autores de tales crímenes el cumplimiento de sanciones en ciertos casos irrisorias y absolutamente desproporcionadas que son cumplidas en libertad.

Otra reflexión que presentan los fallos que dicta la Corte Suprema en casación de oficio respecto de las sentencias de segunda instancia (Cortes de Apelaciones), en los que ha aplicado la media prescripción, en inaudita parte, es que ello vulnera el artículo 8.1. de la Convención Americana de Derechos Humanos y el artículo 14.1 del Pacto Internacional de Derechos Civiles y Políticos de Naciones Unidas, que exigen que las partes sean oídas por el tribunal antes de que este resuelva la materia, especialmente a aquellos que se han visto perjudicados por la comisión del delito contra los derechos humanos o crimen de lesa humanidad. La jurisprudencia uniforme y sostenida de la Corte Interamericana exige que, en los respectivos procesos, las víctimas puedan formular sus pretensiones, presentar elementos probatorios y que estos sean analizados en forma completa y seria a través de una sentencia congruente, fundada en las fuentes del derecho vigente y motivada ${ }^{40}$.

En el caso chileno, la Corte Interamericana ya ha precisado en los casos fallados, que el Estado de Chile no puede argüir ninguna ley o disposición de derecho interno para eximirse de la orden de la Corte de investigar y sancionar penalmente a los responsables de crímenes de lesa humanidad, por lo cual no se puede volver a aplicar el DL $\mathrm{N}^{\circ} 2.191$, ni tampoco podrá argumentarse prescripción, principio non bis in idem ni cualquier otra excluyente de responsabilidad similar, para excusarse de su deber de sancionar a los responsables de tales crímenes $^{41}$.

En el caso chileno, la aplicación de la media prescripción en casos concretos en el tipo de delitos que son crímenes de lesa humanidad ha posibilitado conceder a los condenados la libertad vigilada, con lo cual no existe verdadero y real castigo para los autores de los crímenes de lesa humanidad respectivos, ya que la libertad vigilada consiste en una medida alternativa

\footnotetext{
40 Por todas, Sentencia de la Corte Interamericana, caso Ximena López, párrafo 193; caso Masacres de Ituango, párrafo 296; Caso Baldeón García, párrafo 146

41 Corte Interamericana de Derechos Humanos. Caso Almonacid Arellano y otros vs. Chile. Sentencia sobre excepciones, fondo reparaciones y costas, párrafos 152 y 153.
} 
que suspende el cumplimiento y ejecución de la pena, afectando el derecho de la víctima de tan feroces crímenes y de sus familiares a que los criminales sean efectiva y realmente sancionados y la pena cumplida efectivamente. La insatisfacción de este estándar puede implicar, como lo ha precisado la Corte Europea de Derechos Humanos, una pérdida en la "confianza pública en la preservación del estado de derecho y en la actuación para evitar cualquier aparición de colusión o tolerancia de actos ilegales" ${ }^{\prime 2}$.

En tal sentido, la pena y su ejecución forma parte del derecho a una tutela judicial efectiva de los derechos, en los términos del artículo $8^{\circ}$ de la Convención Americana, ámbitos que se incorporan a los atributos del debido proceso que asegura y garantiza el artículo 19 $N^{\circ} 3$ de la Constitución como derecho fundamental de todas las personas.

Debe tenerse presente, además, como señala la Resolución 2583 (XXIV) del 15 de diciembre de 1969 de la Asamblea General de Naciones Unidas, la cual determina que la sanción de los responsables de crímenes de guerra y lesa humanidad "es un elemento importante para prevenir esos crimenes y proteger los derechos humanos y las libertades fundamentales, y para fomentar la confianza, estimular la cooperación entre pueblos y contribuir a la paz y la seguridad internacionales". La única forma en que esta finalidad sea cumplida es cuando los tribunales establecen sanciones efectivas y proporcionadas al crimen de lesa humanidad cometido por el respectivo autor del mismo.

En esta perspectiva el Estado y sus órganos no pueden tratar a los criminales de lesa humanidad como autores de delitos comunes, aplicándole la normativa penal interna destinada a delitos comunes y no a delitos contra la humanidad, puesto que la normativa penal chilena corresponde a un contexto y una finalidad de sanción de delitos comunes y no de crímenes de lesa humanidad, lo que hace exigible a los tribunales aplicar los estándares determinados por el derecho internacional sobre la materia, como lo ha determinado la Corte Interamericana de Derechos Humanos, en el contexto de un control de convencionalidad en la aplicación del derecho interno, no pudiendo aplicarse las disposiciones de derecho interno contrario a los estándares fijados por el derecho internacional en los crímenes considerados. Debemos recordar que el derecho de los derechos humanos opera bajo un nuevo paradigma, que ya no es estatocéntrico, sino mas bien antropocéntrico, claramente centrado en la dignidad y derechos del ser humano y no en la razón de Estado.

Asimismo, el cumplimiento efectivo de la pena en el caso de crímenes contra la humanidad, posibilita la reparación integral de las víctimas y sus familias, reparación que es también

42 Corte Europea de Derechos Humanos. Caso de Bazorkina vs. Rusia (Aplicación Nº 6948/01). Sentencia de 27 de julio de 2006, párrafo 119. 
obligación del Estado y de sus órganos, de lo cual forma parte el cumplimiento de la pena proporcionada a la gravedad del crimen de lesa humanidad cometido. La reparación integral que se otorga a las víctimas y a sus familiares no se reduce sólo a la indemnización monetaria, ya que ello permitiría a los estados concernidos "pagar" por la impunidad y no castigar penalmente a los responsables. La Corte Europea de Derechos Humanos ya ha fallado casos precisando que los familiares de víctimas de violaciones de derechos humanos, en especial, casos de ejecuciones, tortura o desapariciones, pueden ser objeto de nuevas violaciones de su derecho a no ser sometido a tratos crueles, inhumanos o degradantes, como consecuencia de que la autoridad jurisdiccional concluya la investigación con una sanción ilusoria o inefectiva, fuera de los estándares del derecho internacional exigibles en la materia. Así dicha Corte Europea ha precisado, en el caso Sangariyeva, que se estaba violando en perjuicio de los denunciantes, el derecho a un recurso efectivo en relación con el derecho a la vida y la prohibición de tratos crueles, inhumanos o degradantes, en razón de la conducta de las autoridades que conducen a la permanencia del sufrimiento de los denunciantes ${ }^{43}$.

El cumplimiento de penas efectivas responde también a la finalidad de que los crímenes de lesa humanidad y contra los derechos humanos no queden impunes, negando a sus autores la perspectiva de que el transcurso del tiempo será un elemento que borrará parcial o totalmente la ilicitud internacional del crimen cometido, impidiéndoles a dichos delincuentes alentar conductas que favorezcan la dilación y encubrimiento temporal de los crímenes y con ello verse beneficiados de su propio dolo, lo que es claramente contrario al objeto y fin de la sanción de los delitos en comento, que busca impedir la impunidad y que impone una sanción penal y su cumplimiento en forma proporcionada al crimen cometido, ello deja en evidencia la imposibilidad del otorgamiento de beneficios a los responsables de tales crímenes por el mero hecho que hayan logrado sortear durante cierto lapso la acción de la justicia, como ha ocurrido con las sentencias de la Corte Suprema que estamos comentando.

La proporcionalidad de la pena respecto del crimen de lesa humanidad cometido es un principio básico contenido en todo el derecho internacional que garantiza los derechos humanos respecto de tales conductas, como ocurre con la Convención contra la Tortura y otros Tratos o Penas Crueles, Inhumanos o Degradantes, donde en el artículo $4^{\circ} \mathrm{N}^{\circ} 2$ se determina imperativamente que "todo Estado Parte castigará esos delitos con penas adecuadas en las que se tenga en cuenta su gravedad". Asimismo lo establece el Protocolo Facultativo de la Convención sobre Derechos del Niño de 2002 y la Convención sobre la prevención y el castigo de delitos contra las personas internacionalmente protegidas en su artículo $2^{\circ} \mathrm{N}^{\circ} 2$ y en la Convención Interamericana sobre Desaparición Forzada de Personas, en las cuales los Estados

\footnotetext{
43 Corte Europea de Derechos Humanos. Caso de Batiyeva y X vs. Rusia (Aplicaciones $\mathrm{N}^{\circ} 57953 / 00 \mathrm{y}^{\circ}$ 37392/03). Sentencia de 21 de junio de 2007, párrafo 157.
} 
deben tener en consideración al aplicar las penas la extremada gravedad de los delitos que constituyen crímenes contra la humanidad y los derechos humanos.

Así lo ha precisado también la Comisión Interamericana de Derechos Humanos, órgano de supervigilancia del cumplimiento de buena fe por parte de los Estados y sus órganos, de los compromisos contenidos en el sistema interamericano y de las obligaciones contraídas. Al respecto, la Comisión Interamericana ha determinado que la obligación de sancionar a los responsables requiere que los Estados Parte impulsen "con la debida diligencia el proceso penal, y que sus órganos jurisdiccionales competentes juzguen de manera pronta e imparcial, sancionando en su oportunidad y de acuerdo a la gravedad del delito cometido" 44 , lo cual la Comisión Interamericana lo explicita como una necesidad a la Corte Interamericana en el caso de la Masacre de La Rochela vs. Colombia, solicitando que se ratifique el principio “(...) de que en las investigaciones de graves violaciones de derechos humanos sea imposible reconocer como compatible con la Convención Americana la imposición de penas ínfimas o ilusorias, o que pueden significar una mera apariencia de justicia" ${ }^{45}$.

El ordenamiento convencional internacional de derechos humanos tiene como objeto y propósito ser un instrumento de efectiva protección de los seres humanos afectados en sus derechos y, como lo ha determinado también la Corte Europea de Derechos Humanos, requiere que "sus disposiciones sean interpretadas y aplicadas en orden a hacer sus salvaguardias prácticas y efectivas" ${ }^{4}$.

La Corte Interamericana se ha referido a la obligatoriedad del principio de proporcionalidad de la pena, precisando:

“(...) la Corte estima oportuno señalar que la respuesta que el Estado atribuye a la conducta ilícita del autor de la trasgresión debe ser proporcional al bien jurídico afectado y a la culpabilidad con la que actuó el autor, por lo que se debe establecer en función de la diversa naturaleza y gravedad de los hechos" ${ }^{\prime 4}$.

A su vez, la Corte Suprema de Justicia ya aplicó estos criterios en el caso del homicidio calificado del señor Letelier, donde precisó que "el tribunal estima prudente y de justicia

44 Comisión Interamericana de Derechos Humanos. Informe N²4/98, del 7 de abril de 1998.

45 Corte Interamericana de Derechos Humanos, Caso de la Masacre de La Rochela vs. Colombia, párrafo 191. En el mismo sentido Corte Europea de Derechos Humanos, Caso de Khamila Isayeva vs. Rusia (Aplicación $\mathrm{N}^{\circ}$ 6846/02). Sentencia de 15 de noviembre de 2007, párrafo 164.

46 Corte Europea de Derechos Humanos; Caso de Imakayeba vs. Rusia (Aplicación N ${ }^{\circ} 7615 / 02$ ). Sentencia de 9 de noviembre de 2006, párrafo 139.

47 Corte Interamericana de Derechos Humanos. Caso Vargas Areco, párrafo 108; Caso Hilaire Constantine y Benjamín y otros, párrafo 102; caso Masacre de La Rochela vs. Colombia, párrafo 196. 
mantener las sanciones que determina el fallo de primera instancia, considerando el ámbito, magnitud y proyecciones del crimen y la condición de las personas que en él intervinieron"48.

En los casos analizados debe considerarse el hecho de que los delitos son crímenes de lesa humanidad y contra los derechos humanos; el hecho que los autores actuaron bajo el manto de la impunidad y del ejercicio del poder estatal que debía asegurar los derechos de las víctimas en vez de vulnerarlos a través de crímenes atroces, haciéndolos mucho mas reprochables que en el caso de los delitos comunes, además de considerar necesariamente la importancia de los bienes jurídicos en juego vulnerados (vida, libertad e integridad personal).

A su vez, en los fallos en comento es posible apreciar una falta de adecuada motivación de la sentencia, vale decir, de explicitar los fundamentos y razones que la llevan a determinar una pena, precisando el porque no aplica principios y normas que forman parte del ordenamiento jurídico y que provienen del derecho internacional, las cuales son de aplicación preferente respecto de las normas de derecho penal ordinario interno, evitando así la eventual arbitrariedad de la resolución judicial, de lo contrario, dicha sentencia podría encontrarse en la situación de vulnerar directa e inmediatamente los artículo 8.1 y 25 en concordancia con el artículo 1.1 de la $\mathrm{CADH}$, además del artículo 14 del PIDCP de Naciones Unidas, constituyendo una resolución arbitraria, contraria a derecho, una simple situación de hecho, respecto de la cual no hay cosa juzgada, como lo precisa la Corte Interamericana en el caso Almonacid ${ }^{49}$, entre otros. No creo necesario recordar la gravedad de que el Estado pudiera ser condenado por violación de derechos humanos en virtud de actos jurisdiccionales de la Corte Suprema como ya ocurrió en el caso Almonacid ${ }^{50}$, ya que ello reciente la calidad de las sentencias de dicha Corte y pone en entredicho su voluntad efectiva de cumplir de buena fe las obligaciones básicas de respeto y promoción de derechos humanos o fundamentales que imperativamente exige el artículo $5^{\circ}$ Inciso $2^{\circ}$ de la Constitución y que su propia jurisprudencia en forma uniforme determina.

En los casos en que la Corte Suprema de Justicia no ha aplicado los atributos constitutivos del derecho esencial de toda persona a una tutela judicial efectiva y a un debido proceso, que forman parte del derecho internacional válido y vigente para Chile y que se integran al derecho fundamental asegurado por la Constitución (artículo $19 \mathrm{~N}^{\circ} 3$ ), porque el propio tratado los considera tales y porque el Estado Parte los hace propios al ratificar el tratado, debe explicitar suficientemente las razones para ello y precisar por que aplica normas de derecho penal interno

\footnotetext{
48 Sentencia de la Corte Suprema de Justicia, Rol No 30.174-94, Homicidio calificado de Orlando Letelier, considerando $24^{\circ}$.

49 CIDH. Caso Almonacid Arellano y otros vs. Chile, sentencia de fecha 26 de septiembre de 2006, Serie C $\mathrm{N}^{\circ} 154$, párrafo 145 .

$50 \mathrm{CIDH}$, Caso Almonacid Arellano y otros vs. Chile, sentencia de 26 de septiembre de 2006. Serie C $\mathrm{N}^{\circ}$ 154, párrafo 129.
} 
destinado a casos de delitos comunes a casos de crímenes contra la humanidad, lo que afecta asimismo el mandato constitucional contenido en la reforma a la Carta Fundamental concretada en el año 2005 que determinó, en el artículo 54, inciso $5^{\circ}$, que las disposiciones de un tratado internacional "sólo podrán ser derogadas, modificadas o suspendidas, en la forma prevista en los propios tratados o de acuerdo con las normas generales del derecho internacional", de acuerdo con lo cual, un tribunal no puede inaplicar una norma de derecho internacional vinculante para aplicar una norma de derecho interno contraria al objeto y fin de la primera, que implica, en la práctica, la suspensión de los efectos jurídicos de la norma de derecho internacional válidamente incorporada al derecho interno, con la consiguiente vulneración del propio texto constitucional, además del derecho internacional respectivo que, en estos casos, implica responsabilidad internacional por vulneración de derechos humanos. 
590 Revista Ius et Praxis - AÑo 14 - № 2 